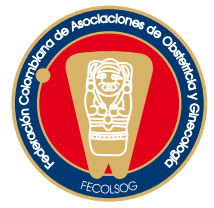

EDITORIAL

\title{
ACERCA DE LA DOBLE PUBLICACIÓN Y EL CUMPLIMIENTO DE OTROS REQUISITOS PARA EL ENVÍO DE MANUSCRITOS A LA REVISTA COLOMBIANA DE OBSTETRICIA Y GINECOLOGÍA
}

\section{Regarding to double publications and the fulfillment of other requirements for sending papers to the Colombian Journal of Obstetrics and Gynecology}

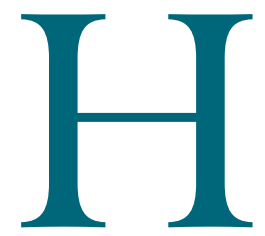

ace ocho años, la Revista Colombiana de Obstetricia y Ginecología inició un proceso de mejoramiento de la calidad científica y editorial, que ha incluido tener un claro proceso de revisión por pares, con tiempos definidos de evaluación y publicación final, presentación de los resúmenes en español e inglés, y en algunos casos publicación de artículos completos en idiomas diferentes al español, idioma oficial de la revista. Las palabras clave en español son homologadas con los descriptores en ciencias de la salud (DeCS) y las palabras clave en inglés con los términos de encabezamiento médico (MeSh), y todos los artículos son sometidos a un riguroso proceso de edición final.

Hoy en día, la Revista Colombiana de Obstetricia y Ginecología está indexada en el Índice Bibliográfico Nacional (Publindex) en categoría A2, en la Scientific Electronic Library Online (SciELO), en la Literatura Latinoamericana y del Caribe en Ciencias de la Salud (LILACS), ofreciendo la versión electrónica a través de la página de la Federación Colombiana de Asociaciones de Obstetricia y Ginecología, y está en proceso de ser incluida en catálogos, bases de datos bibliográficos y empresas de información.
Por otra parte, se amplió el alcance de la misma al incluir además de aspectos de la obstetricia y la ginecología, temas que se relacionen con la salud sexual y reproductiva y con la salud pública, género y violencia con énfasis en el contexto colombiano y latinoamericano, con el ánimo de incrementar la visibilidad internacional de la producción de los investigadores nacionales y regionales en el campo de la salud de la mujer. De este modo, recibimos cada vez más solicitudes para publicación de manuscritos de autores latinoamericanos, algunos de los cuales ya han sido publicados.

Todas las situaciones anteriormente referidas han llevado a una mayor complejidad del proceso editorial y al incremento de manuscritos enviados para publicación. El comité editorial ha hecho la recomendación de incrementar la verificación del cumplimiento de los requisitos para publicación contenidos en las indicaciones a los autores. Por lo tanto, antes de enviar un manuscrito a revisión se les solicita a los autores comprobar el cumplimiento de los requisitos mediante la revisión de la lista de verificación que se encontrará al final en las indicaciones a los autores de las últimas páginas de cada número. 
Queremos sin embargo hacer hincapié en algunos puntos:

Los trabajos deben ser inéditos, es decir, ni el artículo ni parte de él o de su esencia, tablas o figuras, pueden haber sido publicados o estar en vías de publicación en otra revista.

Hemos recibido trabajos que están bajo consideración de otras revistas, sin que se nos notifique a pesar de estar claramente solicitado en las indicaciones a los autores; esta situación ha llevado a la duplicación de artículos, circunstancia que motivó el editorial de la Revista de la Facultad de Medicina de la Universidad Nacional, al que nos adherimos plenamente y que publicamos a continuación de este, por considerar que se debe evitar esta práctica entre los investigadores. Por lo tanto, solicitamos que, a partir de la fecha, en la carta de envío del manuscrito se exprese de manera clara que el documento no ha sido enviado a ninguna otra revista para publicación.

Adjuntamente se debe anexar una carta del autor principal en donde se exprese claramente que el trabajo ha sido leído y aprobado por todos los autores, respaldada con la respectiva firma.
Se debe anexar una carta del autor principal en donde se exprese claramente que el trabajo ha sido leído y aprobado por todos los autores, con firma de cada uno de ellos, en la que aprueban el contenido del manuscrito.

Las referencias deben estar de acuerdo con los formatos utilizados por el Index Medicus y la extensión del artículo no debe ser mayor a 15 hojas.

Cada una de las referencias será verificada por el cuerpo editorial de la Revista, por lo tanto se solicita confirmar la exactitud de la misma, ya que en caso de no poder hacerlo se devolverá el documento a los autores.

Creemos que la comunidad científica nacional y regional tiene ya las competencias que permiten procesos editoriales expeditos y claros que facilitan que cada parte asuma su responsabilidad en el proceso editorial.

Hernando Gaitán, M.D., MSc

Editor 